\section{Comment}

Studies in the United States have shown that children less than 2 years old have a $2-4 \%$ risk of recurrent $H$ influenzae infection. ${ }^{12}$ Such children do not mount a protective immune response to polysaccharide capsule antigens. The child in this study may have reacquired the bacterium from a member of her family as a high proportion of contacts of index patients carry the bacteria, or she may have retained it in her nasopharynx as the antibiotics used to treat epiglottitis do not abolish carriage of $H$ influenzae.

The risk of recurrent serious invasive infection with haemophilus in this child was the same as the risk to a healthy child under 2 years old of acquiring the disease when in contact with an index patient. ${ }^{1}$ The American Academy of Pediatricians recommends that rifampicin be given to the index patient and to all household contacts prophylactically if there is a contact aged less than 49 months or if the patient is less than 25 months old. ${ }^{3}$ There is evidence that such prophylaxis helps to prevent recurrent disease and secondary cases. ${ }^{2}$ It is, however, used rarely in Great Britain; serious $H$ influenzae type b infection and in particular meningitis are thought to be less common than in the United States, yet a survey in Wales showed a similar incidence. ${ }^{4}$ Resistance to rifampicin may occur rarely but rifampicin is not the antibiotic of choice in established disease.

The success of prophylaxis against an organism that colonises sporadically is surprising. Studies of animals suggest that intercurrent viral illness within a group may increase the rate of nasopharyngeal carriage of and promote invasion by the bacteria. Rifampicin eliminates carriage in most people and may therefore help to protect a susceptible person against infection during a high risk period.

$H$ influenzae meningitis has a mortality of $5 \%$ and a risk of handicap of $28 \% .^{5}$ We conclude that there may be a role for prophylaxis with rifampicin in selected contacts until a vaccine is available.

1 Dashefsky B, Wald E, Li K. Management of contacts of children in day care with invasive Haemophilus influenzae type b disease. Pediatrics 1986;78: 939-40.

2 Band JD, Fraser DW, Ajello G. Prevention of Haemophilus influenzae type b disease. FAMA 1984;251:2381-6.

3 American Academy of Pediatrics Committee on Infectious Disease. Revision of recommendations for the use of rifampicin prophylaxis of contacts of patients with Haemophilus influenzae infection. Pediatrics 1984;74:301-2.

4 Howard AJ. Systemic disease produced by Haemophilus influenzae. In: Coles PJ, ed. The pathogenicity of Haemophilus. London: 1987:55-67. (MCI Symposium Series, No 12)

5 Sell SH. Haemophilus influenzae type b meningitis: manifestations and long term sequelae. Pediutr Infect Dis 7 1987;6:775-8.

(Accepled 8 February 1989)

\title{
Pancreatitis associated with Campylobacter jejuni infection: diagnosis by ultrasonography
}

\author{
M H W de Bois, M C Schoemaker, \\ S D J van der Werf, J B C M Puylaert
}

\section{Departments of Internal Medicine and Radiology, Westeinde Hospital, 2512 VA The Hague, The Netherlands M H W de Bois, MD, resident in internal medicine M C Schoemaker, MD, resident in radiology \\ S D J van der Werf, MD, staff member in internal medicine J B C M Puylaert, MD, staff member in radiology}

Correspondence to: $\mathrm{Dr}$ de Bois.

BrMed f 1989;298:1004

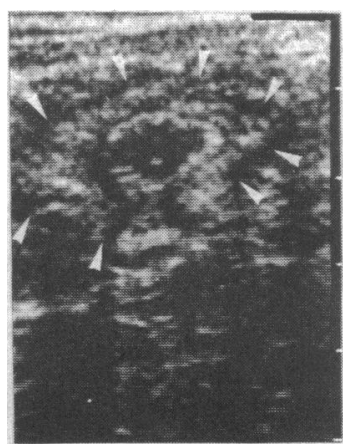

Axial section through ileocaeca valve (arrowheads)

Configuration suggests enteritis caused by $C$ jejuni
Infection with Campylobacter jejuni is a common cause of enteritis. ${ }^{1}$ Several extraintestinal manifestations of the infection have been reported. ${ }^{14}$ Enteritis caused by $C$ jejuni infection has a characteristic appearance on ultrasonography, enabling rapid diagnosis in patients with symptoms in the right lower quadrant of the abdomen. ${ }^{5}$ We describe a case of pancreatitis associated with $C$ jejuni infection, in which the correct diagnosis was indicated by ultrasonography.

\section{Case report}

A 23 year old woman presented with a four day history of fever, diffuse crampy abdominal pain, and nausea with vomiting. She had also had a short period of diarrhoea. She did not have a history of alcohol abuse. On admission she had upper abdominal pain. Palpation of the abdomen disclosed tenderness in the right upper quadrant. On auscultation bowel sounds were normal. Her erythrocyte sedimentation rate was $50 \mathrm{~mm}$ in the first hour and her white cell count $5.4 \times$ $10^{9} / 1$ (with $11 \%$ rod cells). Serum amylase activity was $533 \mathrm{U} / \mathrm{l}$ (normal range 10-90 U/l) and urine amylase activity $2360 \mathrm{U} / \mathrm{l}$ (normal range $0-525 \mathrm{U} / \mathrm{l}$ ). The results of other haematological tests were normal.

An $x$ ray film of the abdomen was normal. Ultrasonography showed a normal gall bladder, pancreas, and bile ducts, but there were a few swollen lymph nodes in the hilum of the liver. Graded compression ultrasonography of the right lower abdominal region showed mural thickening of the terminal ileum and caecum (figure) and moderately enlarged mesenteric lymph nodes. This suggested enteritis caused by $C$ jejuni infection. Further questioning of the patient elicited that she had eaten chicken in a restaurant three days before the onset of her symptoms. Her stools were cultured on plates and grew $C$ jejuni. She made an uneventful recovery, receiving only parenteral fluids. No antibiotics were given, and her serum amylase activity rapidly decreased to normal. The total picture strongly suggested pancreatitis associated with $C$ jejuni infection.

\section{Comment}

Pancreatitis associated with campylobacter is a rare but well recognised disease. Thirteen cases have been reported. ${ }^{2-4}$ The pathophysiological mechanism by which $C$ jejuni elicits or causes pancreatitis is unknown. It may invade the pancreas directly from the adjacent viscera or along the pancreatic duct. ${ }^{23}$ Another possible explanation is that an immune response in the pancreas is initiated by sepsis caused by the bacteria. ${ }^{2}$

The diagnosis of pancreatitis associated with $C$ jejuni infection is usually based on a clinical picture of vomiting, abdominal pain, and raised serum amylase or lipase activity and the presence of $C$ jejuni in cultures of stools. In our patient it was suggested by characteristic findings on ultrasonography of the right lower quadrant of the abdomen. ${ }^{5}$ We conclude that pancreatitis associated with $C$ jejuni infection should be considered with signs of pancreatitis of unknown aetiology. Ultrasonography may then yield a rapid diagnosis.

1 Blaser MJ, Reller L. Campylobacter enteritis. N Engl F Med 1981;305:1444-52. 2 Bär BMAM, van Dam FE. Een patiënt met een door Campylobacter veroorzaakte pancreatitis. Ned Tijdschr Geneeskol 1983;124:2123-5.

Gallagher $P$, Chadwick $P$, Jones DM, Turner L. Acute pancreatitis associated with campylobacter infection. Br J Surg 1981;68:383.

Pitkänen T, Pönka A, Pettersson T, Kosunen TU. Campylobacter enteritis in 188 hospitalized patients. Arch Intern Med 1983;143:215-9.

5 Puylaert JBCM, Lalisang RI, van der Werf SDJ, Doornbos L. Campylobacter ileocolitis mimicking acute appendicitis: differentiation with gradedcompression US. Radiology 1988;166:737-40. 